\title{
THE 6-HOUR SOLUBLE ANTIGEN PRODUCTION TEST FOR COMPARING THE INFECTIVITY OF INFLUENZA VIRUS PREPARATIONS
}

\author{
BY N. B. FINTER* AND A. J. BEALE \\ Public Health Laboratory, Northampton
}

(With 2 Figures in the Text)

\section{INTRODUCTION}

In a new type of test for the infectivity of influenza virus preparations, dilutions of virus are inoculated into groups of eggs, and $6 \mathrm{hr}$. later these are harvested and the amounts of soluble antigen in their chorio-allantoic membranes measured by complement fixation. This test has been termed the $6 \mathrm{hr}$. soluble antigen production test. As shown elsewhere (Beale, 1954; Beale \& Finter, 1956) the relative infectivities of different preparations by this test do not necessarily correspond to those as determined by the conventional method of inoculating several high dilutions of virus into groups of eggs, and determining the proportions with haemagglutinins in their allantoic fluids $72 \mathrm{hr}$. later. In this paper the $6 \mathrm{hr}$. soluble antigen production test is described in detail, and it is shown that reproducible results can be obtained with it. For technical reasons the similar test involving measurement of haemagglutinins in the membranes would be less satisfactory. It is also shown that the age of an egg when virus is inoculated has a considerable influence on the amount of soluble antigen formed in $6 \mathrm{hr}$., with maximum production occurring at about the 12th day of incubation.

\section{MATERIALS AND METHODS}

Virus. The D.S.P. strain of influenza A virus (Hoyle, 1948a) was used throughout, and fertile eggs from a single White Leghorn flock. Seed virus was inoculated in $0.5 \mathrm{ml}$. amounts into the allantoic cavity with a syringe and needle (25-gauge Luer) through a hole drilled in the shell a few millimetres below the margin of the air-space, and over an area of the chorio-allantoic membrane free from blood vessels. A second hole was made into the air-space to prevent regurgitation during inoculation. Both holes were afterwards sealed with nail-polish. Eggs were incubated at $37-38^{\circ} \mathrm{C}$. throughout.

Soluble antigen titrations. The micro complement-fixation test described by Hoyle $(1945,1948 b)$ was used, employing $0.05 \mathrm{ml}$. volume of each reagent and $0.85 \%$ saline as the diluent. The same pool of high-titre human convalescent sera, containing $0.08 \%$ sodium azide and stored at $4^{\circ} \mathrm{C}$, was used in all tests. These sera came from patients infected in 1953 with an $\mathrm{A}^{\prime}$ influenza virus strain which serologically was only distantly related to the D.S.P. strain. There was little cross-

* Member of the External Staff of the Medical Research Council. 
reaction between strain-specific antibodies in the serum pool and the specific antigens of the D.S.P. strain. The pool had a maximum titre of 192 in the complement-fixation test against soluble antigen, and was used in titrations at 1/32. After tests had stood at $4^{\circ} \mathrm{C}$. overnight, the dilution corresponding to $50 \%$ fixation was read for each preparation, and the reciprocal of this gave the titre per $0.05 \mathrm{ml}$. All titres were expressed in logarithmic soluble antigen (SA) units per ml., and converted to standardized values by reference to the titre obtained in parallel with a control soluble antigen preparation. This method of standardizing the results is exemplified in the text and in Table 1.

Chorio-allantoic membrane extracts. At the desired time after inoculation of virus, the chorio-allantoic membranes were harvested from groups of not more than seven eggs. These were all of the same age at harvest, usually between the 12th and 14th day of incubation. After cutting away with scissors a small disk of shell at the pointed end, the contents of the eggs were decanted as described previously (Finter, Liu, Lieberman \& Henle, 1954), leaving the parietal portion of the chorio-allantoic membrane still adherent to the inside of the shell. The shell was twice filled with chilled sterile buffered saline and drained. Then in turn each membrane from the group was removed from the shell, spread out and washed quickly in one Petri dish containing $50 \mathrm{ml}$. of buffered saline and transferred to a second. When all the membranes were accumulated in this dish, they were stirred, drained and transferred to a third dry dish, and finally chopped with scissors into about five or six pieces each and frozen at $-20^{\circ} \mathrm{C}$. Extracts were made after storage at $-20^{\circ} \mathrm{C}$. for between 1 and 5 days. After thawing in the $37^{\circ} \mathrm{C}$. water-bath, the membranes were three times alternately frozen in an alcohol-dry ice bath and thawed in the $37^{\circ} \mathrm{C}$. bath. For each membrane in the pool, $1 \mathrm{ml}$. of buffered saline was then added containing either 500 units of penicillin and $100 \mu \mathrm{g}$. of streptomycin per ml., when the extract was to be tested in ovo, or $0.08 \%$ azide when only to be tested in vitro. After thorough mixing the membranes were centrifuged. The supernatant was decanted and its volume measured.

Buffered saline. $\mathrm{M} / \mathbf{1 5}$ phosphate buffer $(\mathrm{pH} 7 \cdot 0)$ was diluted to $\mathrm{M} / 100$ with $0.85 \%$ saline, and the mixture was autoclaved.

The $6 \mathrm{hr}$. soluble antigen production test. Unless otherwise stated, 14th-day eggs were used. $0.5 \mathrm{ml}$. amounts of two or more dilutions in sterile buffered saline of each virus preparation to be tested were inoculated into groups of at least three eggs by the allantoic route. Six hours later these were chilled in ice to stop virus multiplication. Their chorio-allantoic membranes were harvested and extracts made. From the mean volume of extract per membrane, and its soluble antigen titre per ml., the mean total content of soluble antigen per membrane formed at each dilution of seed virus was obtained.

Infectivity titrations (72 hr. haemagglutinin formation test), and haemagglutinin titrations. The modifications of standard methods described in the succeeding paper (Beale \& Finter, 1956) were used. Results were expressed as logarithmic 50\% infectivity $\left(\mathrm{ID}_{50}\right)$ units per $\mathrm{ml}$., and logarithmic haemagglutinin (HA) units per $\mathrm{ml}$.

All inocula contained a final concentration of 500 units penicillin and $100 \mu \mathrm{g}$. streptomycin per ml. 


\section{EXPERIMENTAL}

\section{Reproducibility of soluble antigen titrations}

Extracts of six different pools of chorio-allantoic membranes infected with influenza virus were titrated on several occasions after storage at $4^{\circ} \mathrm{C}$. for up to 19 days. As usual a control soluble antigen preparation was also titrated twice on each occasion. The logarithmic correction factor needed to convert the mean titre obtained with this to $2 \cdot 75$ (the mean of all titres recorded for this preparation

Table 1. Titres of soluble antigen in six chorio-allantoic membrane extracts after storage at $4^{\circ} \mathrm{C}$. for up to 19 days

Storage of chorio-allantoic membrane extracts at $4^{\circ} \mathrm{C}$. (days)

$\begin{array}{llllll}0 & 1 & 4 & 5 & 7 & 19\end{array}$ Mean

\begin{tabular}{|c|c|c|c|c|c|c|c|}
\hline \multicolumn{8}{|l|}{ Extract no. } \\
\hline 1 & - & $2 \cdot 8$ & $2 \cdot 75$ & - & - & $2 \cdot 7$ & $2 \cdot 75$ \\
\hline 2 & - & $2 \cdot 5$ & $2 \cdot 45$ & - & - & $2 \cdot 4$ & $2 \cdot 45$ \\
\hline 3 & $I \cdot 8$ & 1.95 & $2 \cdot 15$ & $2 \cdot 0$ & $2 \cdot 0$ & $1 \cdot 9$ & $1 \cdot 95$ \\
\hline 4 & $1 \cdot 9$ & $2 \cdot 15$ & $2 \cdot 15$ & $2 \cdot 2$ & $2 \cdot 05$ & $2 \cdot 1$ & $2 \cdot 1$ \\
\hline 5 & 1.55 & 1.45 & $1 \cdot 25$ & 1.35 & 1.35 & - & 1.4 \\
\hline 6 & - & 1.6 & 1.55 & $\mathbf{1 . 5 5}$ & $1 \cdot 55$ & $1 \cdot 4$ & 1.55 \\
\hline $\begin{array}{l}\text { Mean recorded titre of } \\
\text { soluble antigen control } \\
\text { (log) }\end{array}$ & $2 \cdot 75$ & $2 \cdot 7$ & 2.7 & $2 \cdot 6$ & $2 \cdot 6$ & $2 \cdot 6$ & - \\
\hline Log correction factor & $0 \cdot 0$ & +0.05 & +0.05 & $+0 \cdot 15$ & $+0 \cdot 15$ & $+0 \cdot 15$ & - \\
\hline
\end{tabular}

Corrected titres shown are (recorded values $\times$ correction factor). The average over a 1-year period of the recorded titres of the soluble antigen control preparation was $2.75 \log$ SA units per ml. $(2 \cdot 75)-(\log$ mean recorded titre of soluble antigen control $)=\log$ correction factor. Values in black in the table are means of duplicate titrations.

during a 1-year period) was deriyed. This same factor was then added to all other titration values recorded in parallel to give corrected titres. These are shown for the six membrane extracts in Table 1, together with the mean titre of the soluble antigen control on each occasion, and the derived correction factor. It will be seen that when thus corrected, results reproducible within a range of $0.3 \mathrm{log}$ could be obtained in single estimations of a preparation on different occasions, while with duplicate estimations the reproducibility was even greater.

\section{Variation in soluble antigen production in the chorio-allantoic membranes of individual eggs}

Four 12th-day eggs were inoculated with $10^{4} \mathrm{ID}_{50}$ of virus, and $24 \mathrm{hr}$. later their allantoic fluids were harvested and pooled. Three dilutions in buffered saline of this pool were made so that $0.5 \mathrm{ml}$. amounts contained respectively $1 \cdot 3,1.8$ and 2.3 logarithmic haemagglutinin (HA) units, and a number of 13th-day eggs were inoculated with each. Six hours later they were chilled in ice and their membranes 
were harvested in the usual way but from each egg separately. After storage overnight at $-20^{\circ} \mathrm{C}$. an extract of each membrane was made, and duplicate titrations of soluble antigen were carried out on all the extracts in parallel. The results are shown in Table 2. It will be seen that in each of the three groups, the soluble antigen contents of the six individual membranes differed from one another by $0.5 \log$ or less. From further eggs inoculated with $1.8 \log$ HA units of virus, three pools of three membranes each were made. The contents of soluble antigen per

Table 2. The production of soluble antigen in $6 \mathrm{hr}$. in the chorio-allantoic membranes of individual eggs

\begin{tabular}{|c|c|c|c|}
\hline \multirow[b]{2}{*}{ Egg no. } & \multirow{2}{*}{$\begin{array}{l}\text { Inoculum. } \\
\text { Log haem- } \\
\text { agglutinin } \\
\text { units per egg }\end{array}$} & \multicolumn{2}{|c|}{$\begin{array}{l}\text { Total content of soluble } \\
\text { antigen in membrane } \\
\text { log SA units }\end{array}$} \\
\hline & & $\begin{array}{l}\text { Individual } \\
\text { membranes }\end{array}$ & $\begin{array}{l}\text { Mean of } \\
\text { group }\end{array}$ \\
\hline 1 & & $2 \cdot 1$ & \\
\hline 2 & & $2 \cdot 2$ & \\
\hline 3 & 1.3 & $2 \cdot 4$ & 9.34 \\
\hline 4 & $1 \cdot 3$ & $2 \cdot 05$ & $2 \cdot 04$ \\
\hline 5 & & $2 \cdot 55$ & \\
\hline 6 & & $2 \cdot 45$ & \\
\hline 7 & & $2 \cdot 85$ & \\
\hline 8 & & $2 \cdot 75$ & \\
\hline 9 & & $2 \cdot 3$ & 9.67 \\
\hline 10 & & $2 \cdot 85$ & 200 \\
\hline 11 & 1.8 & 2.45 & \\
\hline 12 & & $2 \cdot 8$ & \\
\hline $13-15$ & & - & $2 \cdot 65^{*}$ \\
\hline $16-18$ & & - & $2 \cdot 8^{*}$ \\
\hline $19-21$ & & 一 & $2 \cdot 65^{*}$ \\
\hline 22 & & $3 \cdot 05$ & \\
\hline 23 & & $3 \cdot 1$ & \\
\hline 24 & & $3 \cdot 05$ & \\
\hline 25 & $2 \cdot 3$ & $2 \cdot 75$ & $3 \cdot 0$ \\
\hline 26 & & $3 \cdot 2$ & \\
\hline 27 & & $2 \cdot 85$ & \\
\hline
\end{tabular}

membrane of these pools were all within $0 \cdot 15 \log$ units of one another and of the calculated mean value for the six individual membranes inoculated with the same amount of seed. Thus a pool of three or more chorio-allantoic membranes would seem to provide a fair sample from which the soluble antigen production in response to a given inoculum of virus may be estimated.

Formation of haemagglutinins in chorio-allantoic membranes in $6 \mathrm{hr}$.

In several experiments both haemagglutinins and soluble antigen were estimated in chorio-allantoic membranes harvested $6 \mathrm{hr}$. after inoculation of seed virus. The membranes were frozen and thawed as usual and buffered saline was 
added, but after centrifuging only $0.5 \mathrm{ml}$. of the supernatant was removed (noneluted extract). After mixing the remaining supernatant with the membranes, these were incubated for $6 \mathrm{hr}$. at $37^{\circ} \mathrm{C}$. to allow destruction of inhibitors in the membranes by the agglutinin present (Hoyle, 1952). The membranes were then again centrifuged and the supernatant was decanted (eluted extract). Soluble antigen was estimated in the non-eluted extracts, and haemagglutinins in the eluted extracts. The results of four such experiments, in which the seeds were preparations of chorio-allantoic membrane virus, are shown in Table 3. It will be

\section{Table 3. The production of soluble antigen and haemagglutinins in $6 \mathrm{hr}$. in chorio-allantoic membranes}

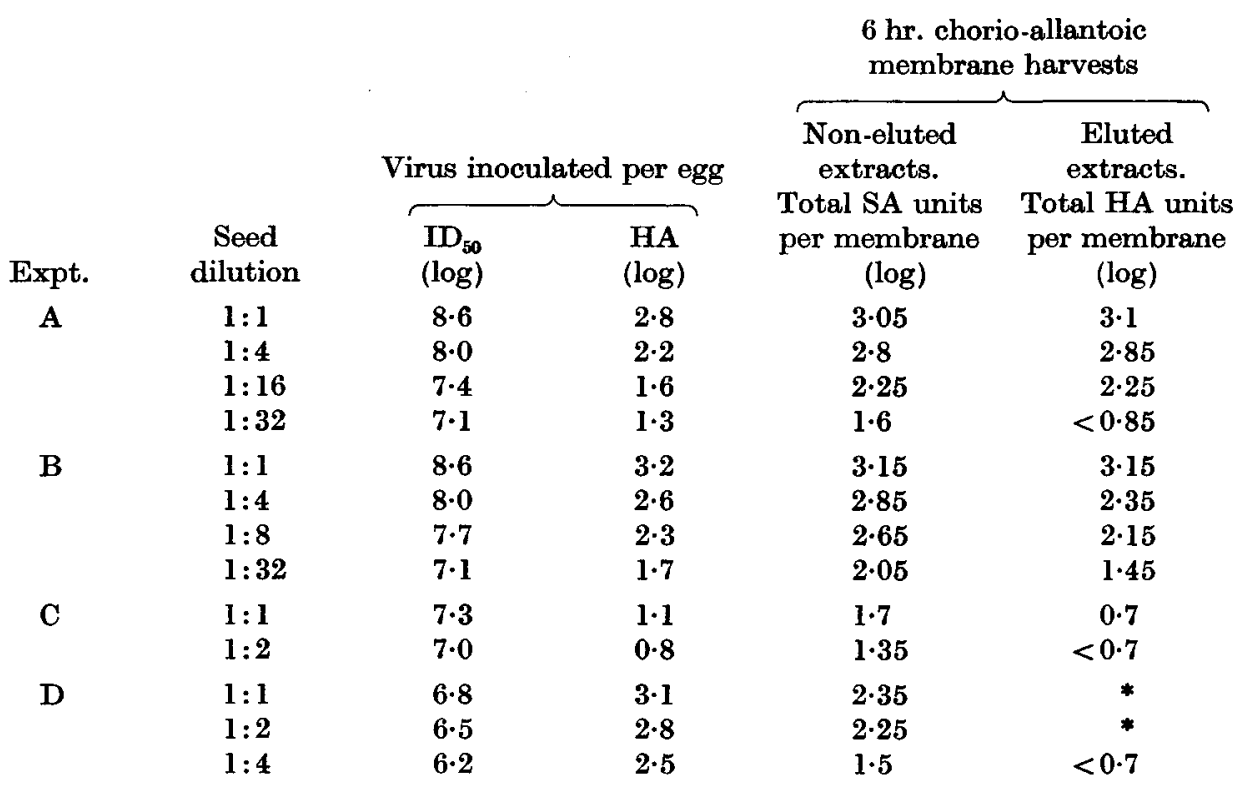

* Abnormal cell patterns obtained; no end-point could be determined.

seen that large amounts of haemagglutinins were found in the eluted extracts when there were large amounts of soluble antigen in the non-eluted extracts. With progressive dilution of the seed virus, smaller and smaller amounts of haemagglutinins were found in the eluted extracts, until eventually none could be detected, although soluble antigen could still be measured in the corresponding non-eluted extracts. In addition, after the more dilute inocula measurement of the haemagglutinins in the eluted extracts was often unsatisfactory. There was much slipping of the cells, and unusual cell patterns were often obtained so that it was difficult to obtain reproducible titration results, and on occasion no end-point could be determined (e.g. Expt. D in Table 3). Titration of haemagglutinins in the non-eluted extracts was even less satisfactory. Thus, compared with the $6 \mathrm{hr}$. soluble antigen production test, a similar test based on estimation of haemagglutinins would be less sensitive and also less reliable after inoculation of relatively small amounts of seed virus. 


\section{The effects of storage on chorio-allantoic membranes}

Allantoic fluid virus was stored at $4^{\circ} \mathrm{C}$. for not more than $24 \mathrm{hr}$. before titration or passage, so as to minimize losses by inactivation or adsorption to urate deposits. It was, however, often convenient to store chorio-allantoic membranes at $-20^{\circ} \mathrm{C}$. for some days before making extracts. In the following experiment a study was made of the effect of such storage on the titres of virus in membranes, and on the results in the $6 \mathrm{hr}$. soluble antigen production test when extracts of stored membranes were used as seeds.

Table 4. The total amounts of virus in extracts made from groups of chorio-allantoic membranes of the same batch after storage at $-20^{\circ} \mathrm{C}$. for different periods

\begin{tabular}{|c|c|c|c|c|}
\hline \multirow{2}{*}{$\begin{array}{l}\text { Length of } \\
\text { storage at } \\
-20^{\circ} \mathrm{C} \text {. } \\
\text { (days) }\end{array}$} & \multicolumn{3}{|c|}{$\begin{array}{c}\text { Mean total virus in } \\
\text { extracts per membrane } \\
\text { (titre } \times \text { volume) (log units) }\end{array}$} & \multirow{2}{*}{$\begin{array}{l}\text { Mean volume } \\
\text { of extract } \\
\text { per membrane } \\
(\log \text { ml. })\end{array}$} \\
\hline & $\mathrm{ID}_{50}$ & HA & $\mathbf{S A}$ & \\
\hline 0 & $9 \cdot 2$ & $2 \cdot 95$ & $3 \cdot 1$ & 0.04 \\
\hline 5 & $9 \cdot 05$ & $3 \cdot 0$ & $3 \cdot 1$ & 0.06 \\
\hline 5 & $9 \cdot 15$ & $2 \cdot 75$ & $3 \cdot 2$ & 0.03 \\
\hline 10 & $9 \cdot 0$ & $3 \cdot 2$ & $3 \cdot 2$ & 0.09 \\
\hline 10 & - & 2.95 & $3 \cdot 1$ & $0 \cdot 05$ \\
\hline 18 & $8 \cdot 6$ & $3 \cdot 1$ & $3 \cdot 15$ & 0.08 \\
\hline 6 months & - & $3 \cdot 1$ & $3 \cdot 2$ & $0 \cdot 13$ \\
\hline
\end{tabular}

A number of 13th-day eggs were inoculated with $10^{4} \mathrm{ID}_{50}$ of virus, and after incubation for $18 \mathrm{hr}$. their chorio-allantoic membranes were harvested. An extract was made at once of ten membranes in the usual way, while the other membranes were stored at $-20^{\circ} \mathrm{C}$. in batches of seven. At intervals during the next 18 days, and also after 6 months, an extract was made from one of these. The results of titrations of these extracts are shown in Table 4. The total amounts of infective virus in the freshly harvested membranes were virtually the same as in those stored for up to 10 days at $-20^{\circ} \mathrm{C}$. The slight apparent drop after 18 days was not significant, since Knight (1944) has shown that, when only five eggs are inoculated with each virus dilution, the minimum significant difference in end-point is $0.67 \mathrm{log}$. The amounts of soluble antigen found were very consistent, even after storage for up to 6 months at $-20^{\circ} \mathrm{C}$., but there was slightly more variation in the amounts of haemagglutinins. Four of these membrane extracts were each tested when freshly made by the $6 \mathrm{hr}$. soluble antigen production test. In Fig. 1 the mean total amount of soluble antigen in the membranes after $6 \mathrm{hr}$. has been plotted against the number of $\mathrm{ID}_{50}$ of seed virus inoculated for each dilution of the four extracts. It will be seen that closely similar results were obtained on passage of the freshly harvested membranes, and of those which had been stored at $-20^{\circ} \mathrm{C}$. for 5,10 and 18 days. Thus it would seem permissible to store chorio-allantoic membranes at $-20^{\circ} \mathrm{C}$. for at least 18 days before passage in the $6 \mathrm{hr}$. soluble antigen production test, although routinely they were not stored for longer than 5 days. 
The effect of egg age on the production of soluble antigen in $6 \mathrm{hr}$.

Samples of about thirty eggs from a single batch were set for incubation on three different days, so that on the required day eggs were available that had been incubated for $15,12 \frac{1}{2}$, and 10 days respectively. High-titre allantoic fluid virus

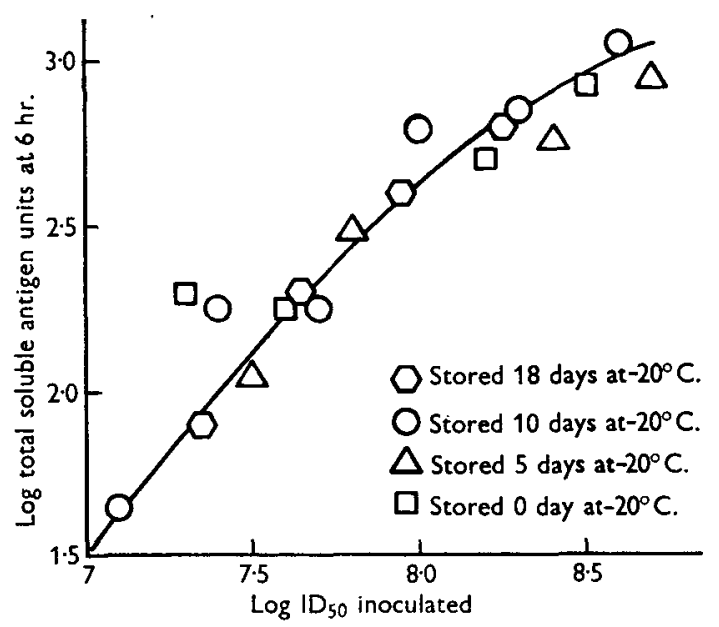

Fig. 1. The relation between soluble antigen production at $6 \mathrm{hr}$. and the number of $\mathrm{ID}_{50}$ of virus inoculated, for four homologous batches of chorio-allantoic membranes which had been stored at $-20^{\circ} \mathrm{C}$. for different periods.

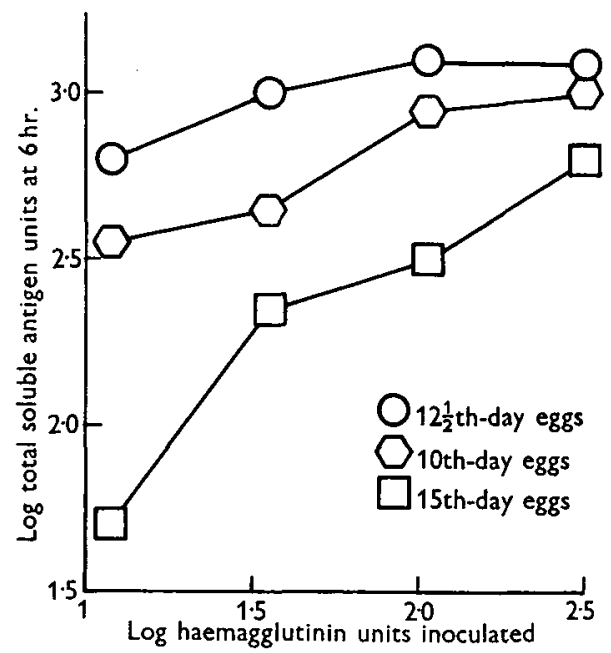

Fig. 2. Soluble antigen production in $6 \mathrm{hr}$. in the chorio-allantoic membranes of eggs of three different ages inoculated in parallel with the same amounts of seed virus.

was grown from dilute seed, and five or six eggs of each age were inoculated with $0.5 \mathrm{ml}$. amounts of virus diluted 1/1, 1/3, 1/9 and 1/27. After incubation for $6 \mathrm{hr}$. the chorio-allantoic membranes were harvested and pooled in groups. Extracts were made and their soluble antigen content determined. The results are shown in Fig. 2. It will be seen that with all four dilutions of seed, the greatest total amounts 
of soluble antigen were found in the membranes of eggs that had been incubated for $12 \frac{1}{2}$ days. With the eggs that had been incubated for only 10 days, consistently less soluble antigen was formed at each seed dilution, and with the 15th day eggs even less. It should however be noted that, owing to differences in the development of the membranes, it was not possible to make identical harvests from the eggs of different ages. There was a reasonably clear-cut demarcation between the parietal portion of the chorio-allantoic membrane (i.e. that lining and adherent to the inside of the shell membrane) and the rest of the membrane when the 15thand $12 \frac{1}{2}$ th-day eggs were harvested. With the 10th-day eggs this was less obvious, and in contrast with the older eggs, the chorio-allantoic membranes were only loosely adherent to the shell membrane, and did not line the whole of the inside of the shell. In addition they were more oedematous and friable than those from the older eggs, and probably rather more variable proportions of the total membrane were obtained in individual harvests.

In a similar experiment the soluble antigen and haemagglutinin production in $6 \mathrm{hr}$. in the membranes of 12th-, 13th-, 14th- and 15th-day eggs was compared. At each of three dilutions of the virus inoculum most soluble antigen was formed in the 12th-day eggs, less in the 13th-day, still less in the 14th-day, and least in the 15th-day eggs. The relative amounts of haemagglutinins fell into the same sequence as those of soluble antigen.

The length of previous incubation of an egg at the time of inoculation of a given amount of virus thus appears to influence considerably the content of soluble antigen in the chorio-allantoic membrane $6 \mathrm{hr}$. later. It follows that in comparisons of soluble antigen production with different seeds, passages should preferably be carried out in parallel with eggs of the same age and batch.

\section{DISCUSSION}

Since it is easier to measure haemagglutinins than soluble antigen, a test based on titration of haemagglutinins in the chorio-allantoic membranes might seem preferable to the $6 \mathrm{hr}$. soluble antigen production test described. In fact this is not so. After inoculation of relatively small amounts of virus it was sometimes difficult to measure the resultant small amounts of haemagglutinins in the $6 \mathrm{hr}$. membrane extracts, as abnormal cell patterns were encountered in the titrations, and on repetition different end-points might be obtained. Such results were probably due to the presence in these extracts of residual amounts of the normal chorio-allantoic membrane haemagglutinin inhibitors (Edney \& Isaacs, 1950). Extracts were incubated at $37^{\circ} \mathrm{C}$. for $6 \mathrm{hr}$. before titration of haemagglutinins, in order to allow destruction of inhibitors by the enzymic action of the virus present (Hoyle, 1952), but when the amounts of virus were small the destruction may not have been complete in the time. Probably for the same reason more seed had to be inoculated to give rise to measurable haemagglutinins in the $6 \mathrm{hr}$. membranes than was required for soluble antigen. Thus the $6 \mathrm{hr}$ soluble antigen test is both more reliable and also more sensitive than the corresponding test based on haemagglutinin measurements. 
The age of eggs when virus is inoculated has been found to influence the amounts of soluble antigen, and haemagglutinins formed in the membranes in $6 \mathrm{hr}$. The greatest production occurred at the 12th day of incubation and less with both younger (10th day) and older (13th- to 15th-day) eggs. The reasons for this have not yet been determined. It has been pointed out that extracts were made from fractions of the whole chorio-allantoic membrane which may not have been identical in the eggs of the different ages, but this would seem an unlikely explanation for the optimum production in 12th-day eggs. Perhaps the response to a virus inoculum may depend on the particular physiological state of the cells in the chorioallantoic membrane at a given stage of development, or on their number. The composition and volume of the allantoic fluid at the time of inoculation may also be factors of importance in this connexion. It may be noted that von Magnus (1951) reported little difference in the rate of multiplication of virus in response to the same inoculum in eggs of between 8 and 15 days of age. However, in his experiments the amounts of virus inoculated were small, and the first harvests made were of allantoic fluid after $24 \mathrm{hr}$. This is in contrast with the large inocula, and the harvests of chorio-allantoic membranes after only $6 \mathrm{hr}$. in the present experiments, and these technical differences may account for the discrepancy.

\section{SUMMARY}

1. The $6 \mathrm{hr}$. soluble antigen production test for comparing the infectivity of influenza virus preparations is described in detail. Dilutions of the preparations are inoculated intra-allantoically into groups of fertile eggs, and after $6 \mathrm{hr}$. of incubation the amounts of soluble antigen formed in their chorio-allantoic membranes are determined. Reproducible results can be obtained.

2. The similar test, in which haemagglutinins in the chorio-allantoic membranes are measured $6 \mathrm{hr}$. after inoculation of seed virus, is less accurate and less sensitive.

3. Eggs of different ages of incubation form different amounts of soluble antigen in their chorio-allantoic membranes in $6 \mathrm{hr}$. when inoculated with the same amounts of virus.

\section{REFERENCES}

Beale, A. J. (1954). A comparison of the soluble antigen production by tissues infected with preparations of extracellular and intracellular influenza virus. J. Hyg., Camb., 52, 225.

Beale, A. J. \& Finter, N. B. (1956). The infectivity of chorio-allantoic membrane influenza virus and incomplete influenza virus by the 6 hour soluble antigen production test. J. Hyg., Camb., 53, 68.

EdNey, M. \& IsaAcs, A. (1950). Interference between inactive and active influenza viruses in the chick embryo. 3. Inhibitor of virus haemagglutination in the chorio-allantoic membrane. Aust. J. exp. Biol. 28, 603.

Finter, N. B., Liu, O. C., Lieberman, L. \& Hente, W. (1954). Studies on host-virus interactions in the chick embryo-influenza virus system. 8. An experimental analysis of various de-embryonation technics. J. exp. Med. 100, 33.

HoyLe, L. (1945). An analysis of the complement-fixation test in influenza. J. Hyg., Camb., 44, 170.

Hoyce, L. (1948a). The growth cycle of influenza virus A. A study of the relations between virus, soluble antigen and host cell in fertile eggs inoculated with influenze virus. Brit. $J$. exp. Path. 29, 390. 
Hoyse, L. (1948b). Technique of the complement fixation test in influenza. Mon. Bull. Minist. Hlth Lab. Serv. 7, 114.

HoYx, L. (1952). The multiplication of complement-fixing antigen and red-cell agglutinin in the chorio-allantoic membrane of fertile eggs inoculated with influenza virus. J. Path. Bact. 64, 419.

KNIGHT, C. A. (1944). Titration of influenza virus in chick embryos. J. exp. Med. 79, 487.

von Magnus, P. (1951). Propagation of the PR 8 strain of influenza A virus in chick embryos. 1. The influence of various experimental conditions on virus multiplication. Acta path. microbiol. scand. 28, 250.

(MS. received for publication 25. vII. 55) 